\title{
Spatial distribution of intact polar lipids in North Sea surface waters: Relationship with environmental conditions and microbial community composition
}

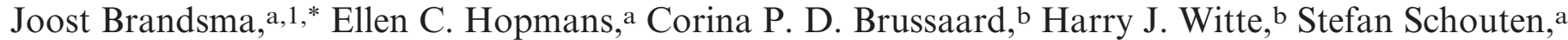 \\ and Jaap S. Sinninghe Damsté ${ }^{a}$
}

a Royal Netherlands Institute for Sea Research, Department of Marine Organic Biogeochemistry, Den Burg, The Netherlands

b Royal Netherlands Institute for Sea Research, Department of Biological Oceanography, Den Burg, The Netherlands

\begin{abstract}
We characterized and quantified the intact polar lipid (IPL) composition of the surface waters of the North Sea and investigated its relationships with environmental conditions, microbial abundances, and community composition. The total IPL pool comprised at least 600 different IPL species in seven main classes: the glycerophospholipids phosphatidylcholine (PC), phosphatidylglycerol (PG), and phosphatidylethanolamine (PE); the sulfur-bearing glycerolipid sulfoquinovosyldiacylglycerol (SQDG); and the nitrogen-bearing betaine lipids diacylglyceryltrimethylhomoserine (DGTS), diacylglyceryl-hydroxymethyltrimethylalanine (DGTA), and diacylglyceryl-carboxyhydroxymethylcholine (DGCC). Although no significant relationships were found between the IPL composition and environmental parameters, such as nutrient concentrations, distance-based ordination yielded distinct clusters of IPL species, which could in turn be tentatively correlated with the predominant microbial groups. SQDGs and PGs, as well as PC species containing saturated fatty acid moieties, were related to picoeukaryote abundances and PC species with polyunsaturated fatty acid (PUFA) moieties to nanoeukaryote abundances. The PEs were likely of mixed cyanobacterial-bacterial origin, whereas DGTA and DGCC species were mainly associated with cyanobacteria. DGTSs were likely derived from either pico- or nanoeukaryotes, although the DGTS species with PUFAs also showed some relationship with cyanobacterial abundances. Concentrations of the algal-derived IPLs showed strong positive correlations with chlorophyll $a$ concentrations, indicating they may be used as biomarkers for living photosynthetic microbes. However, direct relationships between the IPLs and microbial groups were relatively weak, implying that the predominant IPLs in marine surface waters are not derived from single microbial groups and that direct inferences of microbial community compositions from IPL compositions should be considered with care.
\end{abstract}

Intact polar lipids (IPLs) are the basic building blocks of biological membranes and consequently occur ubiquitously in the natural environment. Their molecular structure typically encompasses a glycerol backbone with ester-linked fatty acids attached to the stereospecific number $(s n)-1$ and $s n-2$ positions (the core lipid), and a hydrophilic (polar) head group at the $s n-3$ position (Fahy et al. 2005). Many of these head groups contain essential elements such as phosphorus, nitrogen, or sulfur, and their biosynthesis may be related to nutrient availability to the organism (Minnikin et al. 1974; Benning et al. 1995; Martin et al. 2011). Certain IPL classes or constituent fatty acids are synthesized predominately, or sometimes exclusively, by specific microbial groups and can thus be used as chemotaxonomic markers (Shaw 1974; Lechevalier and Lechevalier 1989; Sturt et al. 2004). Furthermore, IPL molecules are thought to be degraded rapidly upon cell death and therefore predominately derived from living (microbial) cells (White et al. 1979; Harvey et al. 1986). Based on these two concepts, the distribution of IPLs in environmental samples should reflect the composition of the extant microbial community, and IPL analysis thus has the potential to provide valuable information complementary

*Corresponding author: (J.Brandsma@soton.ac.uk).

${ }^{1}$ Present address: University of Southampton, Faculty of Medicine, Lipidomics Research Group, Southampton, United Kingdom to that obtained by microbiological and molecular techniques.

The development of rapid and comprehensive methods for the direct analysis of IPLs (Brügger et al. 1997; Fang and Barcelona 1998; Rütters et al. 2002a) has increased our knowledge of their sources and dynamics in the marine environment, in particular in subsurface sediments (Rütters et al. 2002b; Zink et al. 2003; Lipp and Hinrichs 2009). However, the number of studies of IPL compositions of marine waters is still limited. Schubotz et al. (2009) showed the presence of various glycerophospholipids, betaine lipids, and glycosyl-glycerolipids, as well as the sulfur-bearing glycerolipid sulfoquinovosyldiacylglycerol (SQDG), in surface waters of the Black Sea. The IPL assortment was inferred to represent a mixed community of eukaryotic algae, cyanobacteria, and heterotrophic bacteria, but no direct comparison with the phytoplankton composition was made. Van Mooy and Fredricks (2010) analyzed IPLs in the euphotic zone of the eastern South Pacific. They observed a similar suite of IPLs as in the waters of the Black Sea, and tentatively identified broadly defined phytoplankton groups as their likely sources. Popendorf et al. (2011) again observed similar IPLs in the western North Atlantic Ocean and used a combination of observational data, isotope tracing, and culture incubations to link the production of IPLs to different planktonic groups. Finally, studies of IPL production under phosphate limitation in open ocean surface waters have shown that plankton can substitute glycerophospholipids with betaine 
lipids or SQDGs in settings where phosphate is scarce (Van Mooy et al. 2006, 2009; Popendorf et al. 2011), a mechanism that is well known from microbial cultures (Rose 1989; Benning et al. 1995; Martin et al. 2011).

Although these studies have increased our knowledge of IPLs in marine waters, there is still a strong need for observational and comparative data to improve our understanding of their distribution, sources, and dynamics in the world's oceans and their chemotaxonomic potential. Here we present a detailed analysis of the IPL composition in the surface waters of the North Sea and distinct adjacent water masses in the northeast Atlantic Ocean, English Channel, and Skagerrak (Fig. 1). We statistically compare the IPL data with contemporaneous environmental and microbiological data (Brandsma 2011) in order to determine if environmental conditions directly influence the IPL composition at this location, and to determine what relationships exist between the IPLs and the microbial community composition.

Environmental and microbial biogeographic context of the study area

The environmental conditions and microbial biogeography of the North Sea during the time of sampling are discussed by Brandsma (2011), but a summary of these results is given here and in Table 1. The North Sea is a relatively shallow shelf sea (average depth around $90 \mathrm{~m}$ ) with a stratified water column during the summer months (Elliott and Clarke 1991). It receives influxes of well-mixed nutrient-rich water from the northern Atlantic Ocean through the English Channel and around the Shetland Islands, as well as low-salinity nutrient-poor water from the Baltic Sea through the Skagerrak (Otto et al. 1990; Ducrotoy et al. 2000). In general, the environmental parameters showed a west-east gradient from the "Atlantic" stations (Shetland Islands and English Channel) to the stations in the North Sea. Temperature increased eastwards from $11^{\circ} \mathrm{C}$ to $18^{\circ} \mathrm{C}$, whereas salinity decreased from 35.4 to 34.6 (Fig. 2A,B). The Skagerrak and Norwegian coastal area were further distinguished from the rest of the North Sea by their lower salinity (around 32). Concentrations of dissolved inorganic nitrogen, phosphorus, and silicate were high at the Atlantic stations and near-coastal sites, but substantially lower over much of the North Sea (Fig. 2CE). N : P ratios of dissolved inorganic nutrients ranged from around 16 at the Atlantic stations to less than 5 in the central North Sea, whereas high ratios (up to 25) were measured in the Skagerrak and the eastern English Channel (Fig. 2F)

Throughout most of the study area chlorophyll $a$ concentrations were fairly low $\left(0.2-0.5 \mu \mathrm{g} \mathrm{L}^{-1}\right)$, except in the eastern English Channel and southern North Sea, where concentrations reached $9.2 \mu \mathrm{g} \mathrm{L}^{-1}$ (Fig. 3A; Table 1). Within the microbial community, the distribution of the cyanobacteria was generally converse to that of the eukaryotes (Fig. 3B-D). Cyanobacteria were most abundant in the central North Sea (up to $9.6 \times 10^{4}$ cells $\mathrm{mL}^{-1}$ ), whereas smaller picoeukaryotes were most abundant in the English Channel and southern and western North Sea (up to $2.4 \times 10^{4}$ cells $\mathrm{mL}^{-1}$ ), and larger nanoeukaryotes were

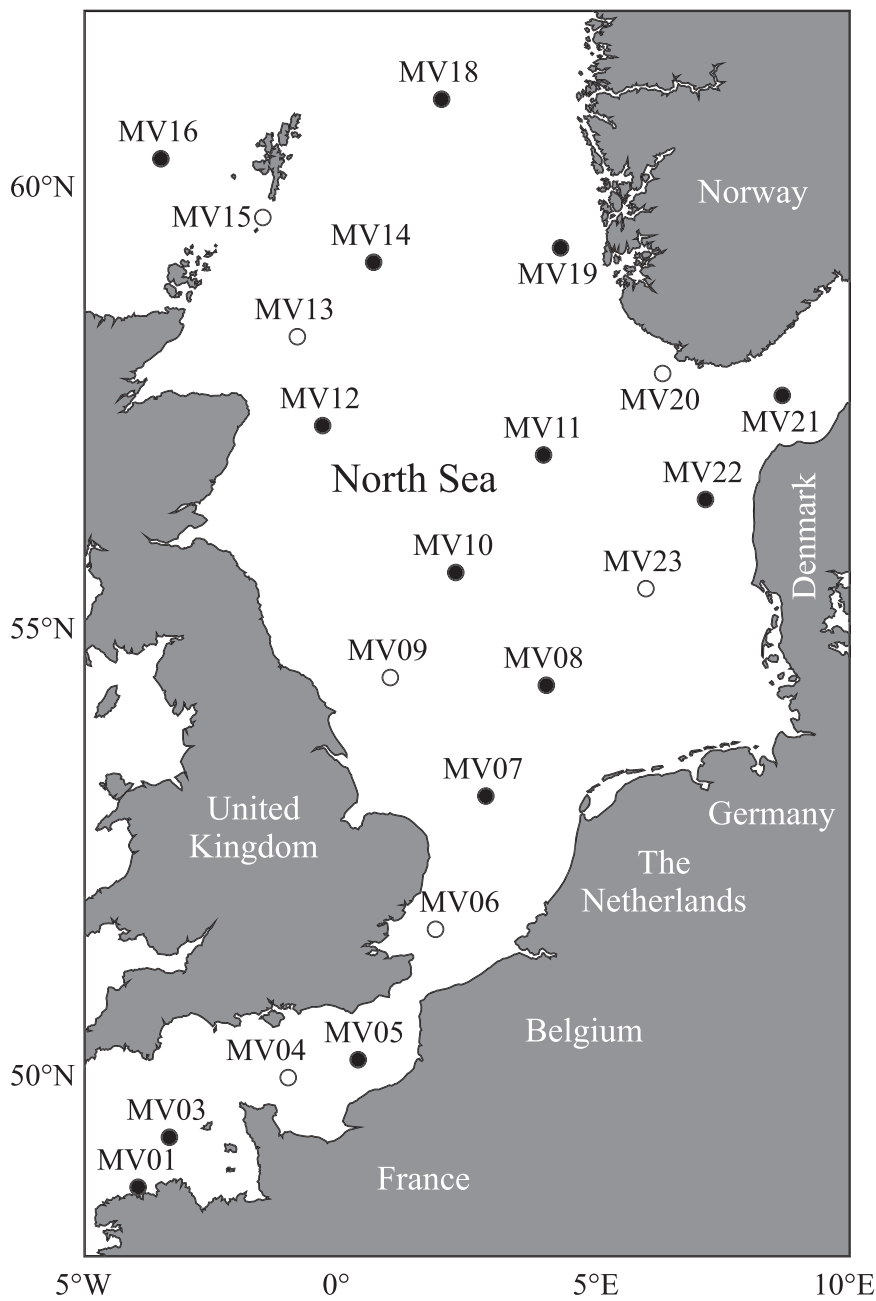

Fig. 1. Station map of the R/V Pelagia cruise MICROVIR (64PE217) in July 2007. Samples for environmental analyses, microbial abundances, and IPL analysis were taken at all of the stations, with the exception of MV23 (no bacterial abundances). Chlorophyll $a$ concentrations were determined only for stations with filled symbols. All sampling was performed at $10 \mathrm{~m}$ water depth.

most abundant around the Shetland Islands and in the eastern North Sea and Skagerrak (up to $1.2 \times 10^{4}$ cells $\mathrm{mL}^{-1}$ ). In addition, at Sta. MV05 in the eastern English Channel a bloom of large diatoms (Bacillariophyceae) took place at the time of sampling. The bacterial distribution was generally unrelated to the distributions of the cyanobacteria and eukaryotes, although some of the highest abundances of heterotrophic bacteria $\left(1.8 \times 10^{6}\right.$ cells $\mathrm{mL}^{-1}$ ) were found at the aforementioned diatom bloom (Fig. 3E).

\section{Methods}

Cruise and sampling-All samples for this study were taken during the R/V Pelagia cruise MICROVIR (virus control of the picophytoplankter Micromonas pusilla population dynamics in European waters; cruise number 64PE217), which took place in July 2007 from 


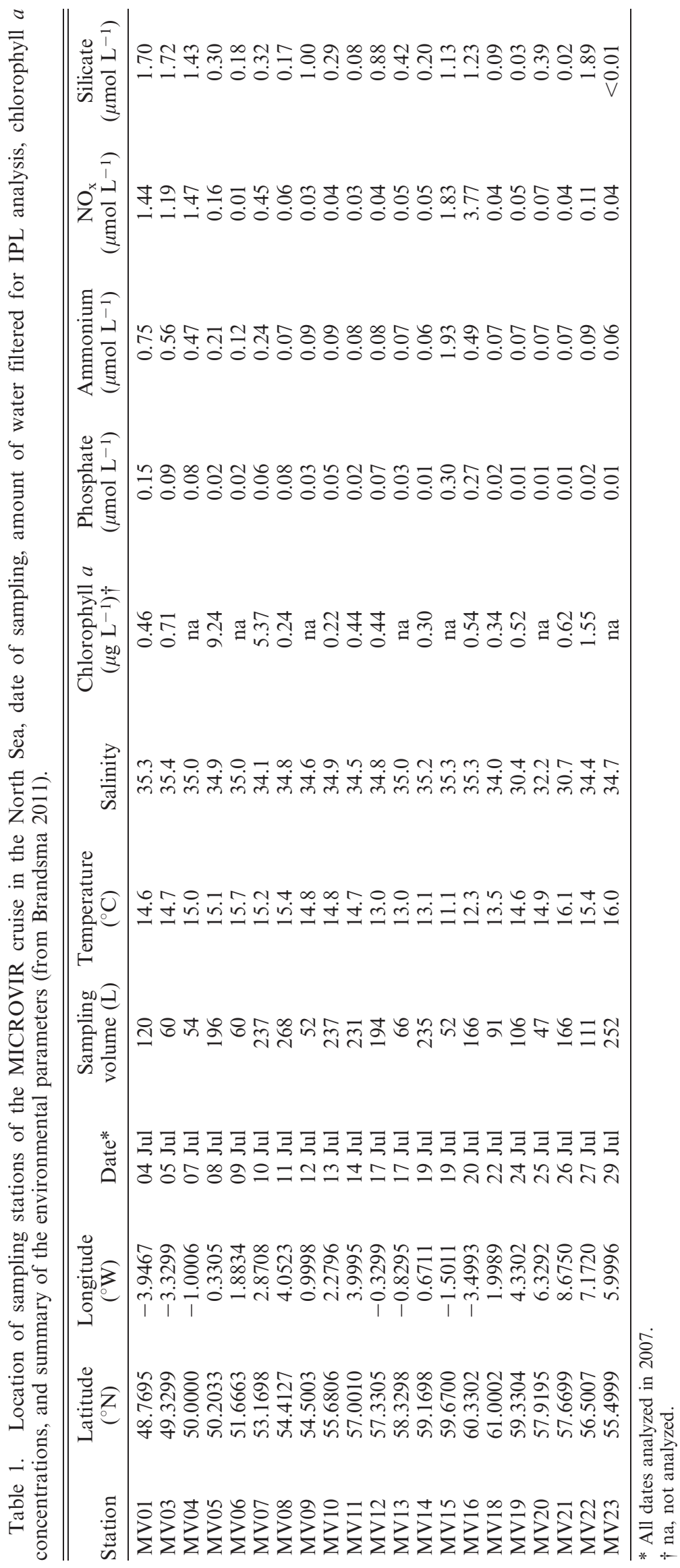


A) Temperature $\left({ }^{\circ} \mathrm{C}\right)$

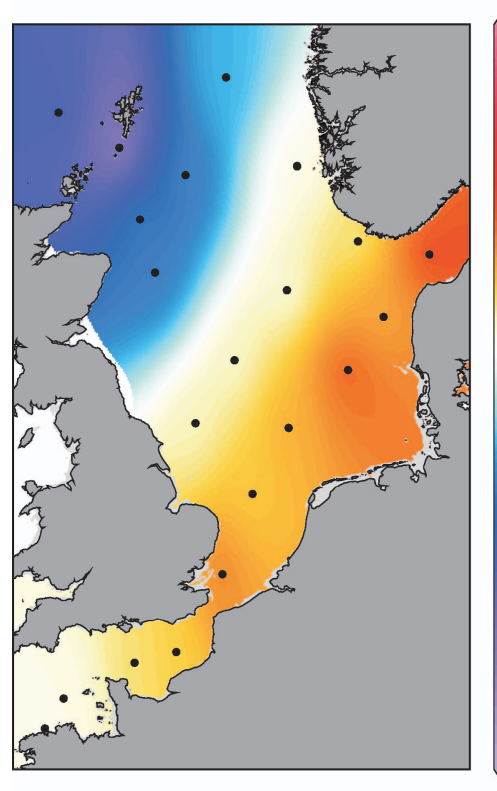

D) Nitrogen $\left(\mu \mathrm{mol} \mathrm{L}^{-1}\right)$

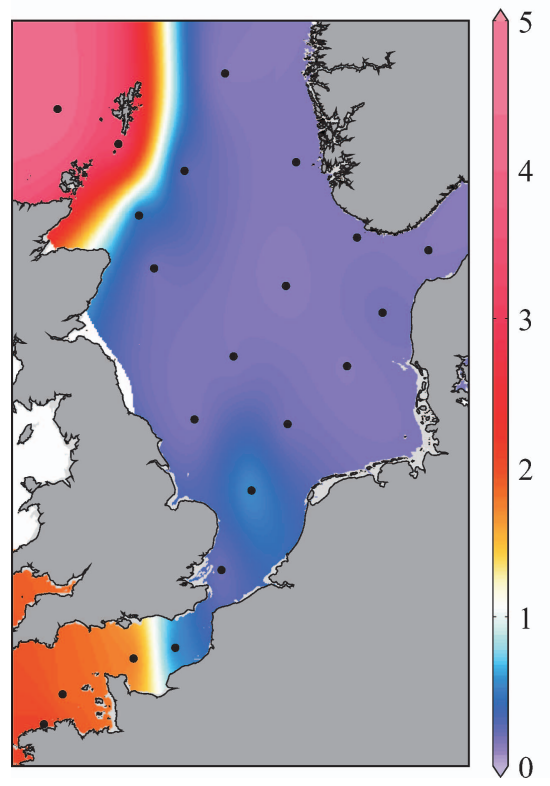

B) Salinity

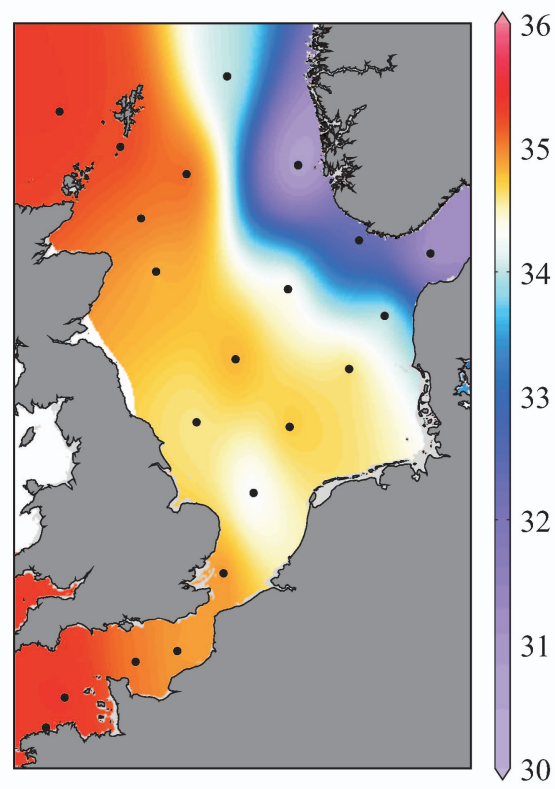

E) Phosphorous $\left(\mu \mathrm{mol} \mathrm{L}^{-1}\right)$

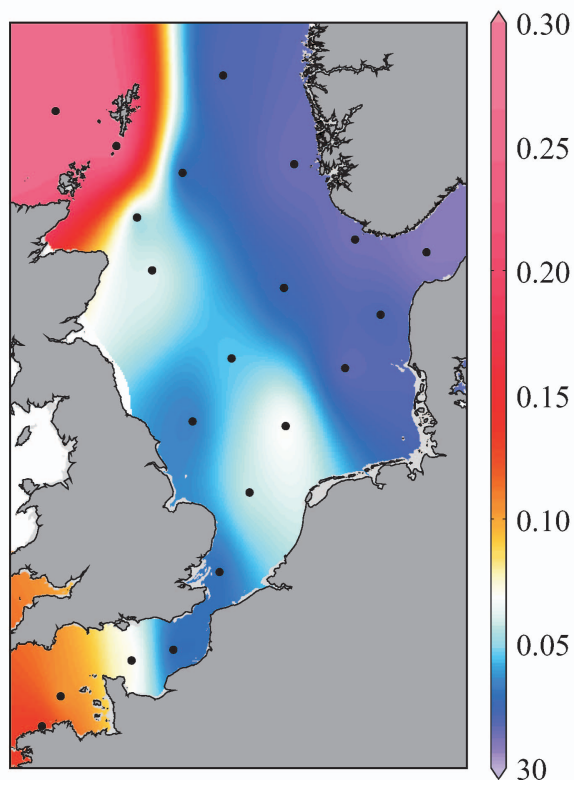

C) Silicate $(\mu \mathrm{mol} \mathrm{L}-1)$

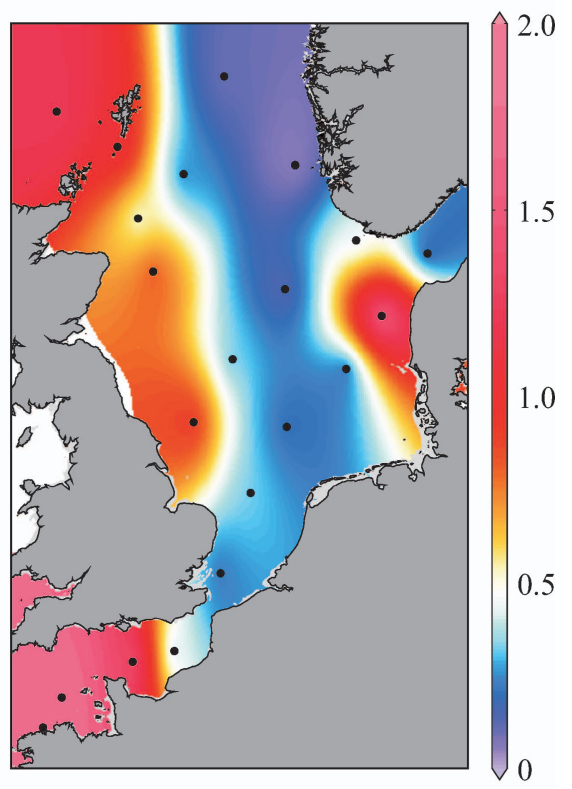

F) N:P ratio

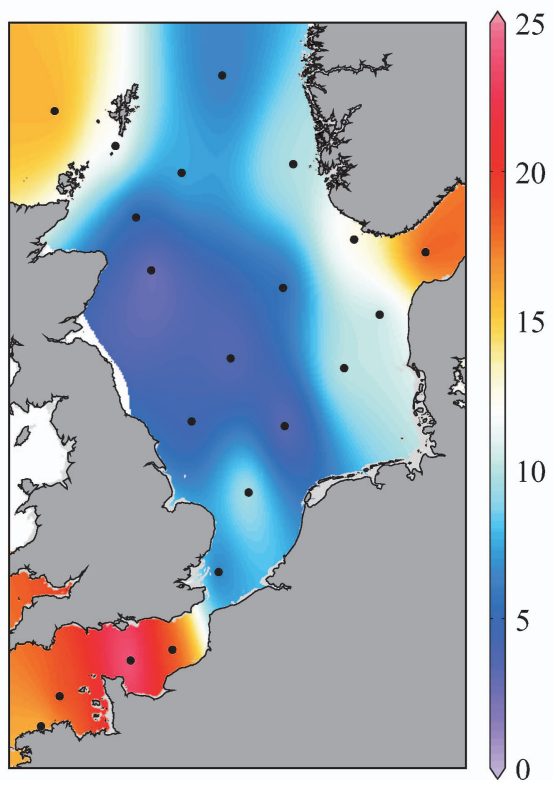

Fig. 2. (A) Temperature, (B) salinity, $(\mathrm{C}-\mathrm{E})$ concentrations of dissolved inorganic nutrients $(\mathrm{Si}, \mathrm{N}$, and $\mathrm{P})$, and $(\mathrm{F}) \mathrm{N}: \mathrm{P}$ ratio in the surface waters of the North Sea (data obtained from Brandsma 2011). Contour maps were obtained using the freeware package Ocean Data View 4 (Schlitzer 2010).

Brest (France) to Texel (The Netherlands), and covered the entire North Sea, plus several adjacent water masses (Fig. 1). A total of 21 stations were sampled at a water depth of $10 \mathrm{~m}$ for temperature, salinity, dissolved inorganic nutrients, and chlorophyll $a$ (Table 1), as well as microbial abundances and phytoplankton composition (see Brandsma 2011 for details). In addition, particulate matter for IPL analysis was sampled by in situ filtration of the surface water over $0.7-\mu \mathrm{m}$ mesh $\mathrm{GF} / \mathrm{F}$ filters $(292-\mathrm{mm}$ diameter, precombusted at $450^{\circ} \mathrm{C}$ for $12 \mathrm{~h}$; Whatman). All filters were stored frozen at $-80^{\circ} \mathrm{C}$ for the duration of the cruise and until extraction in the lab.

IPL analysis-The particulate matter filters were freeze-dried before the IPLs were extracted using a modified Bligh-Dyer procedure (Bligh and Dyer 1959; Vancanneyt et al. 1996; Rütters et al. 2002a). Briefly, the filters were extracted ultrasonically three times for $10 \mathrm{~min}$ in a solvent mixture of methanol, dichloromethane, and phosphate buffer $(2: 1: 0.8 \mathrm{v}: \mathrm{v}: \mathrm{v})$. After 
A) Chlorophyll $a\left(\mu \mathrm{g} \mathrm{L}^{-1}\right)$

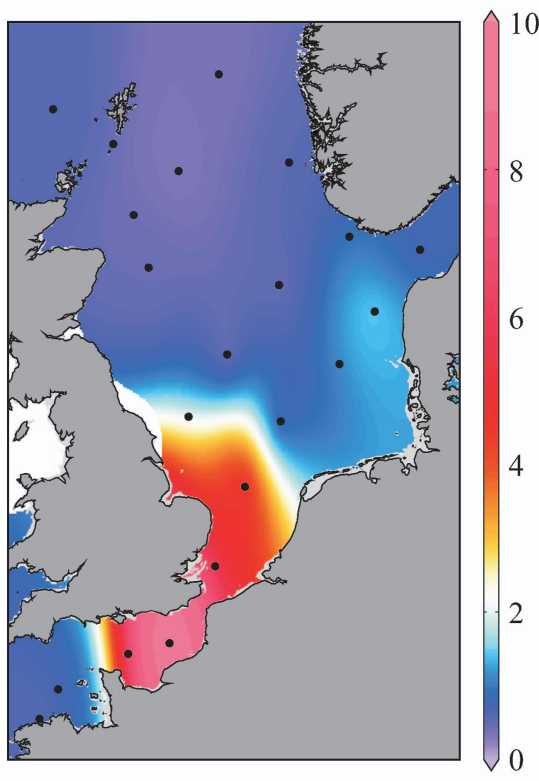

B) Picoeukaryotes $\left(\times 10^{4}\right.$ cells $\left.\mathrm{mL}^{-1}\right)$

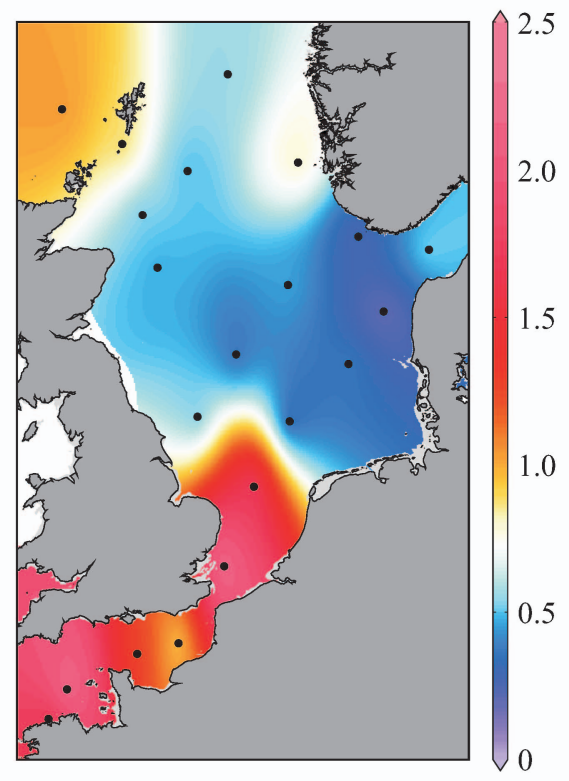

C) Nanoeukaryotes $\left(\mathrm{x} 10^{4}\right.$ cells $\left.\mathrm{mL}^{-1}\right)$

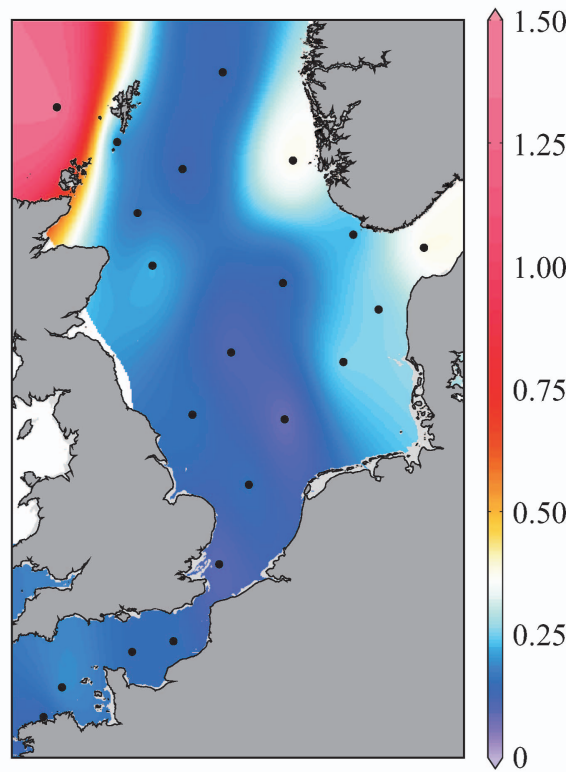

D) Cyanobacteria $\left(\times 10^{5}\right.$ cells $\left.\mathrm{mL}^{-1}\right)$

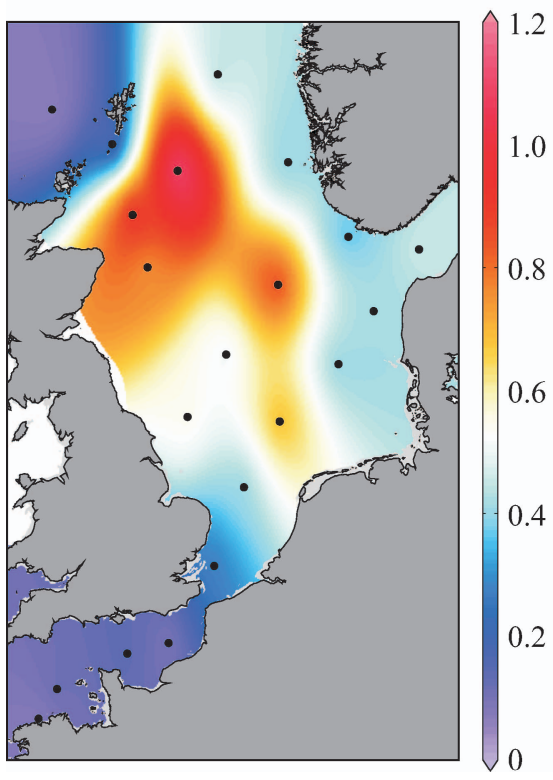

E) Bacteria $\left(\times 10^{6}\right.$ cells $\left.\mathrm{mL}^{-1}\right)$

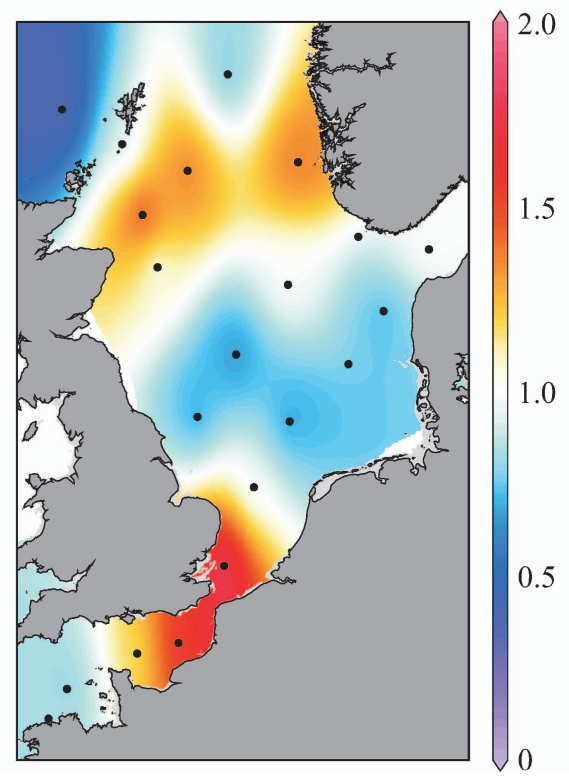

Fig. 3. (A) Chlorophyll $a$ concentrations and abundances of the major microbial groups, (B) picoeukaryotes, (C) nanoeukaryotes, (D) cyanobacteria, and (E) bacteria, in the surface waters of the North Sea (data obtained from Brandsma 2011). Note that a bloom of large diatoms (Bacillariophyceae) was sampled in the eastern English Channel at Sta. MV05. Contour maps were obtained using the freeware package Ocean Data View 4 (Schlitzer 2010).

sonication, the supernatants were phase separated by adding additional dichloromethane and buffer to a final solvent ratio of $1: 1: 0.9(\mathrm{v}: \mathrm{v}: \mathrm{v})$. The organic phases containing the IPLs were then collected and the aqueous phases re-extracted three times with dichloromethane. Finally, the extracts were dried under a stream of nitrogen gas. Before analysis, the extracts were redissolved in a mixture of dichloromethane and methanol $(9: 1 \mathrm{v}: \mathrm{v})$ at a concentration of $10 \mathrm{mg} \mathrm{mL}^{-1}$, and aliquots were filtered through $0.45-\mu \mathrm{m}$ mesh True
Regenerated Cellulose syringe filters (4-mm diameter; Grace Alltech).

IPL analysis of the extracts was performed by highperformance liquid chromatography electrospray ionization tandem mass spectrometry (HPLC-ESI-MS ${ }^{2}$ ), using chromatographic conditions as described by Jaeschke et al. (2009). Initially, the extracts were analyzed in positive and negative ion mode (two separate runs) using a datadependent $\mathrm{MS}^{2}$ routine in which a full scan $(\mathrm{m} / \mathrm{z} 300$ 1000) was followed by fragmentation of the base peak of 
the resulting mass spectrum. Source and fragmentation parameters for positive ion analysis were as described by Boumann et al. (2006). For analysis in negative ion mode the following source parameters were used: capillary temperature $250^{\circ} \mathrm{C}$, sheath gas $\left(\mathrm{N}_{2}\right)$ pressure 49 (arbitrary units), auxiliary gas $\left(\mathrm{N}_{2}\right)$ pressure 21 (arbitrary units), spray voltage $-4.2 \mathrm{kV}$, and source collision-induced dissociation (CID) $7 \mathrm{~V}$. The collision energy was set at $-35 \mathrm{~V}$ with a collision gas (Ar) pressure of $0.8 \mathrm{mTorr}$ for fragmentation in negative ion mode. Identification of the major IPL classes was based on diagnostic fragmentation patterns in the $\mathrm{MS}^{2}$ mass spectra for the glycerophospholipids (Brügger et al. 1997; Fang and Barcelona 1998), betaine lipids (Vogel et al. 1990; Benning et al. 1995; Kato et al. 1996), and SQDG (Keusgen et al. 1997). Subsequently, targeted mass spectrometric experiments were used to elucidate the structural diversity within each of the identified IPL classes, and for quantification of the IPL classes and their constituent species. IPLs with a phosphatidylcholine (PC), diacylglyceryl-trimethylhomoserine or diacylglyceryl-hydroxymethyl-trimethylalanine (DGTS or DGTA), or diacylglyceryl-carboxyhydroxymethylcholine (DGCC) head group were measured in positive ion mode by parent ion scanning $(\mathrm{m} / \mathrm{z} 300-1000)$ of fragment ions diagnostic for their polar head groups (i.e., $\mathrm{m} / \mathrm{z} 184, \mathrm{~m} / \mathrm{z}$ 236, and $\mathrm{m} / \mathrm{z} 178$, respectively). DGTS and DGTA both produce a fragment ion at $\mathrm{m} / \mathrm{z} 236$, but were distinguished by their elution order on the HPLC, with the more polar DGTA eluting later (Dembitsky 1996). IPLs with a phosphatidylglycerol (PG), phosphatidylethanolamine (PE), or SQDG head group were measured in positive ion mode by neutral loss scanning $(\mathrm{m} / \mathrm{z} 300-1000)$ for losses of $189 \mathrm{Da}, 141 \mathrm{Da}$, and $261 \mathrm{Da}$, respectively. The $\mathrm{MS}^{2}$ settings for detection of these IPLs were identical to those described above, but for detection of SQDG the collision energy for the neutral loss assay was set to $-25 \mathrm{~V}$. The carbon number and degree of unsaturation of the fatty acid moieties of the various IPLs were calculated using the $\mathrm{m} / \mathrm{z}$ of the molecular species, and these are denoted as such below (i.e., $\mathrm{C}_{30: 1}$ PG refers to an IPL with a PG head group and the subscript indicates the total number of carbon atoms and double bond equivalents of the fatty acid moieties; note that this does not include the glycerol moiety). Information on individual fatty acid compositions of the predominant IPL species was based on fragment ions or neutral losses diagnostic for fatty acids obtained in the data-dependent MS2 experiments (Brügger et al. 1997).

For quantification of the PGs, PCs, PEs, SQDGs, and DGTSs, the peak areas of each IPL class (total ion current) and their constituent IPL species (mass chromatogram) were compared with the respective peak areas of known quantities of authentic standards. The standards used in this study were $\mathrm{C}_{16: 0} / \mathrm{C}_{16: 0} \mathrm{PC}, \mathrm{C}_{16: 0} / \mathrm{C}_{16: 0} \mathrm{PG}$, and $\mathrm{C}_{16: 0} /$ $\mathrm{C}_{16: 0} \mathrm{PE}$ (all Avanti Polar Lipids, Alabaster), and a mixture of SQDGs, which contained predominately $\mathrm{C}_{16: 1} / \mathrm{C}_{18: 2}$ SQDG, but also small amounts of SQDGs with $\mathrm{C}_{16: 0-16: 1}$, $\mathrm{C}_{18: 0-18: 1}$, and $\mathrm{C}_{20: 5}$ fatty acid combinations (Lipid Products, Redhill). In addition, a standard of $\mathrm{C}_{14: 0} / \mathrm{C}_{18: 1}$ DGTS was purified from IPL extracts of Isochrysis galbana (CCMP 1323) biomass using semi-preparative HPLC
(Jaeschke et al. 2009) and flow injection analysis-mass spectrometry (Smittenberg et al. 2002). Structural identification and purity of this standard $(\sim 70 \%)$ were confirmed by comparing its ${ }^{1} \mathrm{H}$ and ${ }^{13} \mathrm{C}$ nuclear magnetic resonance spectra with previously published spectra of DGTS (Evans et al. 1982). As no standards were available for DGTA and DGCC, the concentrations of these IPL classes were estimated by comparing their peak areas (total ion current in the full scan data acquired as part of the positive ion data-dependent $\mathrm{MS}^{2}$ experiment) with those of DGTS, which has a similar molecular structure (Dembitsky 1996; Kato et al. 1996). Limits of detection were $50-100 \mathrm{pg}$ on column for the glycerophospholipids, $100 \mathrm{pg}$ on column for DGTS, and $1 \mathrm{ng}$ on column for SQDG. All IPL quantifications were reproducible within a $10 \%$ error between duplicate runs, and the instrument response was monitored by repeated analysis of blanks and quantitative standards every 10 samples.

Statistical analysis - Compositional similarities between the stations were visualized by distance-based ordination, using the dedicated software package PRIMER 6 with the PERMANOVA+ add-on (both PRIMER-E, Lutton). BrayCurtis similarity matrices of the stations were calculated based on their IPL composition (for both the total concentrations of the IPL classes and the concentrations of the IPL species), and the results were plotted using multidimensional scaling (MDS) ordination. Cluster analysis was used to group stations with comparable IPL compositions (threshold at $>80 \%$ similarity) and vector plots were used to visualize the relationship between the ordination and the raw data (i.e., microbial abundances and IPL concentrations). Furthermore, the measures of dependence between the IPL similarity matrices and similarity matrices based on the environmental parameters and the microbial community composition were determined by calculating their Spearman's rank correlation coefficients (RELATE test in the PRIMER software package).

Relationships between both total and individual IPL concentrations and environmental and microbial parameters were then tested statistically in Systat 13 (Systat Software). The measure of association between each pair of variables was determined by calculating their Spearman's rank correlation coefficient $(r)$. This test was chosen as many of the variables showed a highly skewed distribution. Only variable associations with corrected probability values $(p)$ of less than 0.05 were considered significant and are reported here.

\section{Results}

Structural diversity of IPLs-The IPL diversity in the surface waters of the North Sea and adjacent areas comprised seven main classes: the glycerophospholipids PC, PG, and PE; the sulfur-bearing glycerolipid SQDG; and the nitrogen-bearing betaine lipids DGTS, DGTA, and DGCC (Fig. 4). In addition, trace amounts of the glycerolipids mono- and digalactosyldiacylglycerol were detected as well. Each of the main IPL classes contained a large variety of IPL species with different fatty acid 


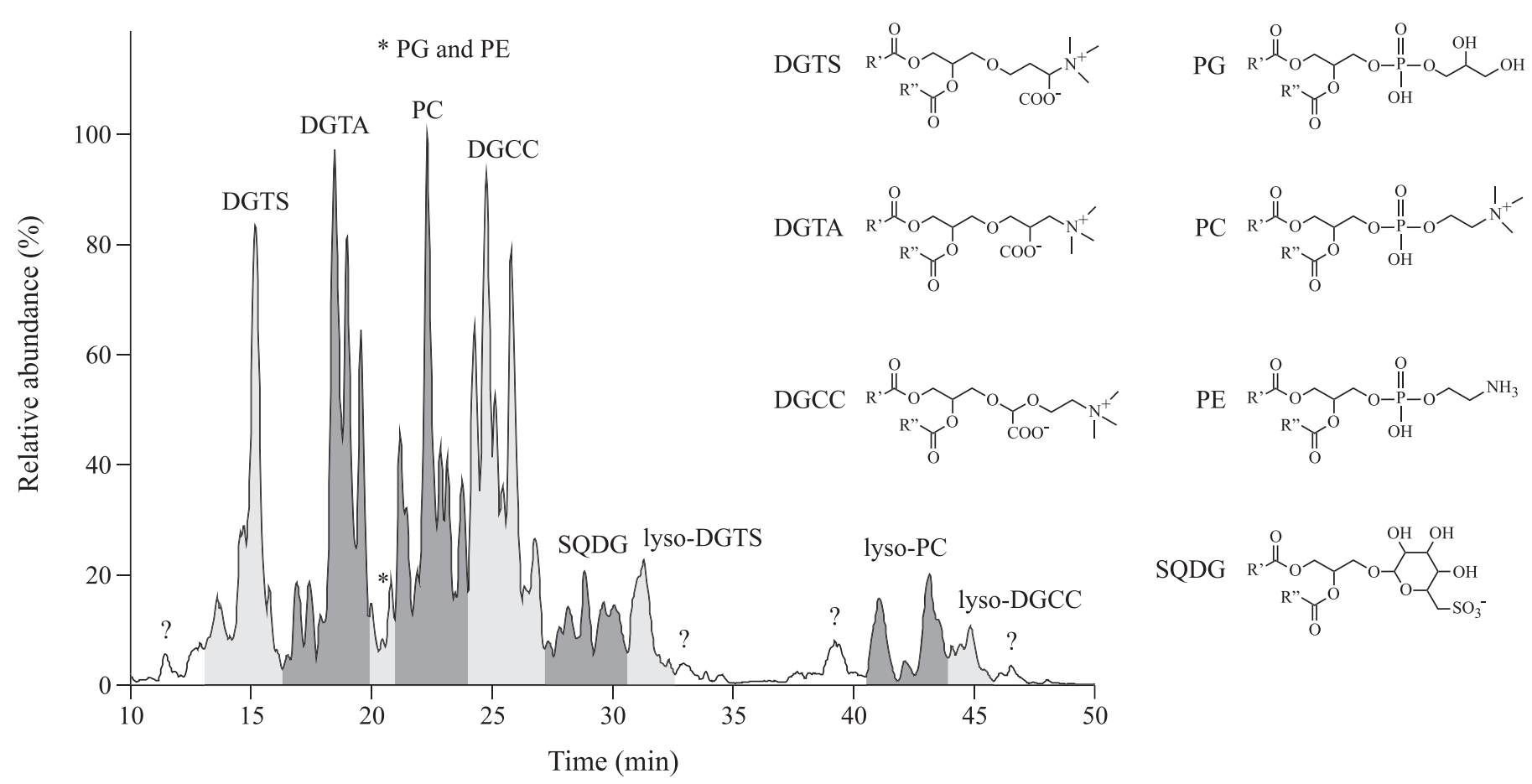

Fig. 4. Partial base peak chromatogram (Gaussian smoothed) of the HPLC-ESI-MS 2 analysis of IPLs in the particulate matter sampled at Sta. MV10, showing the IPL classes that predominate in marine surface waters throughout the North Sea. Unidentified peaks are indicated with a question mark. Example structures are given for each of the detected IPL classes: DGTS, DGTA, PG, PE, PC, DGCC, and SQDG. Each peak comprises a wide range of IPLs with the same head group, but different fatty acids at the $s n-1$ and $s n-2$ positions ( $\mathrm{R}^{\prime}$ and $\mathrm{R}^{\prime \prime}$ in the example structures). Note that because of differences in mass spectral response factors between the IPL classes, their relative abundances in the base peak chromatogram are not indicative of their respective absolute abundances.

compositions. A considerable difference in the number of species was noted between PG and SQDG (around 40 each), and the other IPL classes (around 100 each). The fatty acid compositions of the predominant IPL species can be found in the Web Appendix, Table A1 (www.aslo.org/ lo/toc/vol_57/issue_4/0959a.html). Of the different classes, SQDG showed the least structural variation, containing mostly combinations of $\mathrm{C}_{14}, \mathrm{C}_{16}$, and $\mathrm{C}_{18}$ saturated or monounsaturated fatty acids. For the other IPL classes, the variation in composition was larger, with fatty acid chain lengths generally ranging from $\mathrm{C}_{12}$ to $\mathrm{C}_{22}$. Within $\mathrm{PG}$ and DGTS the shorter chain lengths $\left(\mathrm{C}_{14}\right.$ to $\left.\mathrm{C}_{18}\right)$ predominated, whereas DGCC had mostly longer-chain fatty acids $\left(\mathrm{C}_{18}\right.$ to $\mathrm{C}_{22}$ ). Although the majority of the fatty acids in each of the IPL classes had combinations of fatty acids with even chain lengths, some odd-carbon number fatty acids $\left(\mathrm{C}_{13}\right.$ to $\left.\mathrm{C}_{19}\right)$ were also detected. These were most common in $\mathrm{PE}$ and PC, but absent in DGCC. Finally, long-chain $\mathrm{C}_{18}$ to $\mathrm{C}_{22}$ polyunsaturated fatty acids (PUFAs) were particularly predominant in PC, DGTA, and DGCC, but absent in SQDG.

IPL concentrations and spatial distribution-Quantification of the IPLs at the different stations shows that overall SQDG was the most abundant IPL class (Fig. 5), with concentrations generally ranging from 0.5 to $5 \mu \mathrm{g} \mathrm{L}^{-1}$, but up to $45 \mu \mathrm{g} \mathrm{L}^{-1}$ in the eastern English Channel (Fig. 6A). The species $\mathrm{C}_{28: 0}, \mathrm{C}_{30: 1}, \mathrm{C}_{30: 0}$, and $\mathrm{C}_{32: 1}$ SQDG constituted the bulk of the total SQDG concentration throughout
(70\% $\pm 5 \%$; Web Appendix, Table A2). At most stations the relative abundances of these four species were comparable, but elevated contributions of $\mathrm{C}_{28: 0} \mathrm{SQDG}$ were measured around the Shetland Islands (up to $49 \%$ of the total SQDG) and in the southern North Sea (34\%). In addition, elevated contributions of $\mathrm{C}_{32: 0}$ SQDG and $\mathrm{C}_{34: 1}$ SQDG were detected in the southeastern North Sea $(11 \%$ and $6 \%$, respectively), whereas in the eastern English Channel $\mathrm{C}_{32: 1}$ SQDG predominated (32\%).

PC was generally the most abundant of the glycerophospholipids at all stations, followed by PG and PE (Fig. 5). Total PC concentrations generally ranged from 80 to $440 \mathrm{ng} \mathrm{L}{ }^{-1}$, but up to $1.2 \mu \mathrm{g} \mathrm{L}^{-1}$ in the eastern English Channel (Fig. 6B). There was no single predominant PC species, although 10 species were on average more common (each 3-9\% of the total PC; Table A2.2), with the PUFAbearing $\mathrm{C}_{38: 6} \mathrm{PC}$ having the highest abundance overall (7$22 \%$ ). Total PG concentrations generally ranged from 30 to $320 \mathrm{ng} \mathrm{L}^{-1}$, but up to $750 \mathrm{ng} \mathrm{L}^{-1}$ in the eastern English Channel (Fig. 6C). The species $\mathrm{C}_{32: 2}, \mathrm{C}_{32: 1}, \mathrm{C}_{34: 2}$, and $\mathrm{C}_{36: 2}$ PG constituted the bulk of the total PG concentration at the different stations $(57 \% \pm 3 \%)$, with their relative abundances showing little variation (Table A2.3). In addition to these species, another six PGs comprising a wide range of $\mathrm{C}_{12: 0}$ to $\mathrm{C}_{20: 4}$ fatty acids were present in elevated amounts at some of the stations (up to $14 \%$ ). Finally, total PE concentrations generally ranged from 1 to $100 \mathrm{ng} \mathrm{L}^{-1}$, with the stations in close proximity to the coast or in front of major river systems generally having the 


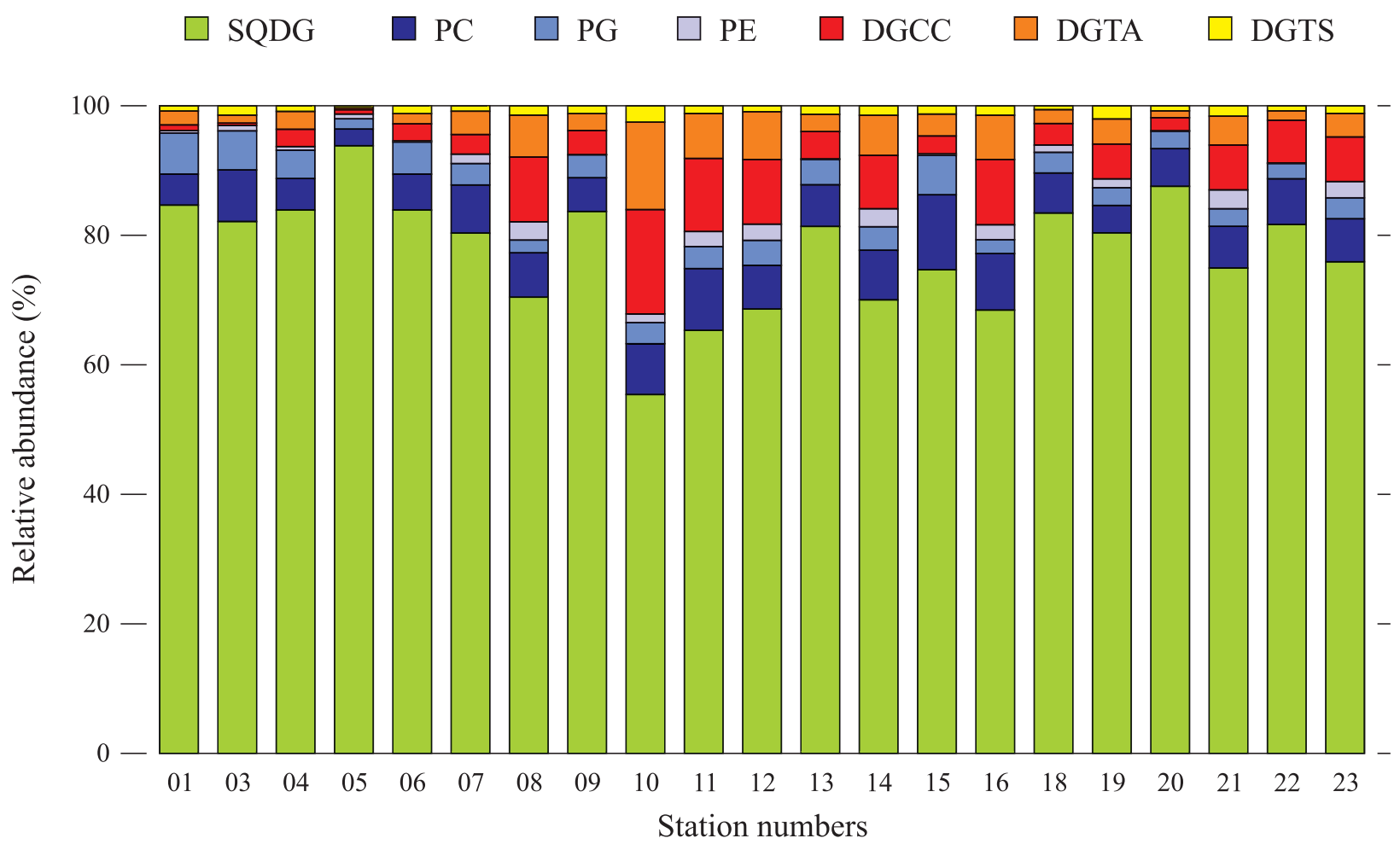

Fig. 5. Relative abundances of the predominant IPL classes in the surface waters of the North Sea. The abundances are presented as a fraction of the total quantified IPL content at each station (i.e., within the mass window of $\mathrm{m} / \mathrm{z} 300-1000$ and excluding minor unidentified compounds, but including estimated concentrations of DGTA and DGCC).

lowest values, and a maximum of $350 \mathrm{ng} \mathrm{L}^{-1}$ in the eastern English Channel (Fig. 6D). The PE species composition was more variable than in PC and PG, with many species predominating at some of the stations, but having low abundances at the rest. Nonetheless, the species $\mathrm{C}_{32: 2}, \mathrm{C}_{32: 1}$, $\mathrm{C}_{34: 2}, \mathrm{C}_{34: 1}$, and $\mathrm{C}_{38: 6} \mathrm{PE}$ were generally more common, constituting on average $47 \% \pm 2 \%$ of the total PE concentration throughout (Table A2.4).

Of the betaine lipid classes, total DGTA and DGCC concentrations were higher than total DGTS concentrations at most stations, although care should be taken as DGTA and DGCC concentrations could only be estimated because of the lack of authentic standards (see Methods). In general, DGCC was up to 2.5 times more abundant than DGTA (Fig. 5), with estimated concentrations ranging between 20 and $410 \mathrm{ng} \mathrm{L}^{-1}$ for total DGCC, and between 60 and $190 \mathrm{ng} \mathrm{L}^{-1}$ for total DGTA (Fig. 6E,F). $\mathrm{C}_{34: 5}, \mathrm{C}_{36: 6}$, $\mathrm{C}_{36: 5}, \mathrm{C}_{38: 6}$, and $\mathrm{C}_{44: 12}$ DGCC were the predominant DGCC species throughout, although $\mathrm{C}_{44: 12}$ DGCC was generally not detected in the English Channel. $\mathrm{C}_{38: 6}$ DGCC was the most abundant species in the central part of the North Sea, whereas elevated contributions of $\mathrm{C}_{30: 0}$ and $\mathrm{C}_{32: 0}$ DGCC were observed in the southeastern North Sea and the eastern English Channel. Within DGTA, the species containing short-chain saturated or monounsaturated fatty acids (particularly $\mathrm{C}_{30: 1}$ and $\mathrm{C}_{33: 1}$ DGTA) predominated in the English Channel and southern and western North Sea, whereas the species containing longerchain PUFAs (particularly $\mathrm{C}_{38: 6}, \mathrm{C}_{40: 10}, \mathrm{C}_{42: 11}$, and $\mathrm{C}_{44: 12}$ DGTA) predominated in the rest of the North Sea, in the
Skagerrak, and around the Shetland Islands. Finally, total DGTS concentrations generally ranged from 15 to $90 \mathrm{ng} \mathrm{L}^{-1}$, but up to $160 \mathrm{ng} \mathrm{L}^{-1}$ in the eastern English Channel (Fig. 6G). As with PC, no predominant DGTS species could be identified, although $\mathrm{C}_{28: 0}, \mathrm{C}_{30: 1}, \mathrm{C}_{32: 2}$, $\mathrm{C}_{32: 1}$, and $\mathrm{C}_{34: 2}$ DGTS were on average more common and together comprised $33 \% \pm 2 \%$ of the total DGTS concentration at most stations (Table A2.5). Although the relative abundances of these five species were mostly comparable throughout the study area, elevated contributions of $\mathrm{C}_{30: 1}$ DGTS were measured in the central North Sea (up to 29\%). In addition, a further 11 DGTS species were present in moderate and highly variable amounts (up to $6 \%$ each). In particular, elevated concentrations of $\mathrm{C}_{34: 1}$ DGTS were detected in the English Channel and southern North Sea (12\%), whereas the PUFA-containing $\mathrm{C}_{36: 5}$ DGTS predominated around the Shetland Islands (24\%).

Statistical relationships between IPLs and environmental and microbial parameters-To investigate the potential sources of IPLs and the effect of environmental conditions on the IPL composition, we statistically compared the IPL concentrations with the environmental and microbiological parameters measured in the same set of samples (Brandsma 2011). Trends in the data were initially identified by plotting the stations according to their compositional similarity (using MDS ordination of BrayCurtis similarity matrices and cluster analysis) and correlating the ordination with the raw IPL, environmen- 
A) Total SQDG $\left(\mu \mathrm{g} \mathrm{L}^{-1}\right)$

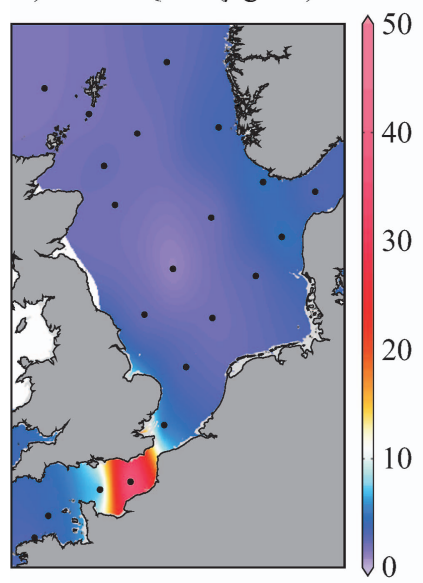

E) Total DGCC $\left(\mu \mathrm{g} \mathrm{L}^{-1}\right)$

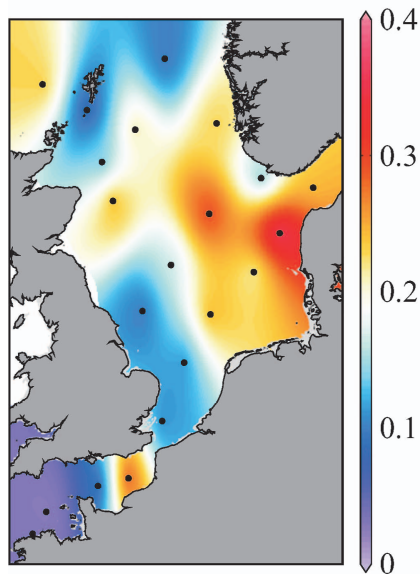

B) Total PC $\left(\mu \mathrm{g} \mathrm{L}^{-1}\right)$

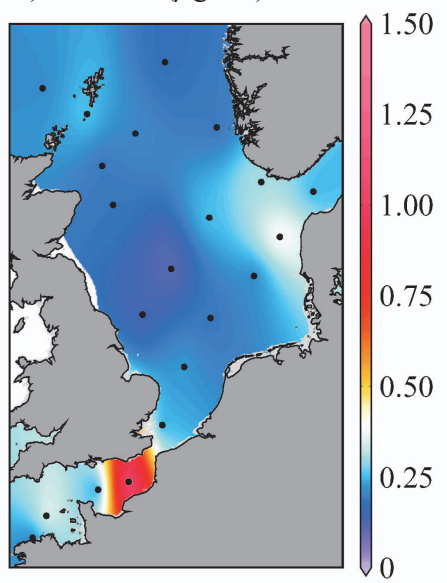

F) Total DGTA $\left(\mu \mathrm{g} \mathrm{L}^{-1}\right)$

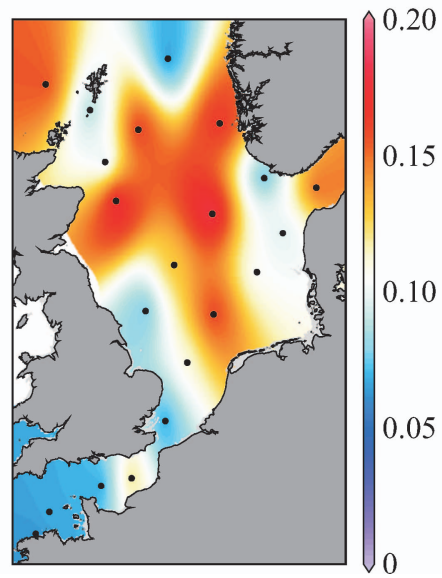

C) Total PG $\left(\mu \mathrm{g} \mathrm{L}^{-1}\right)$

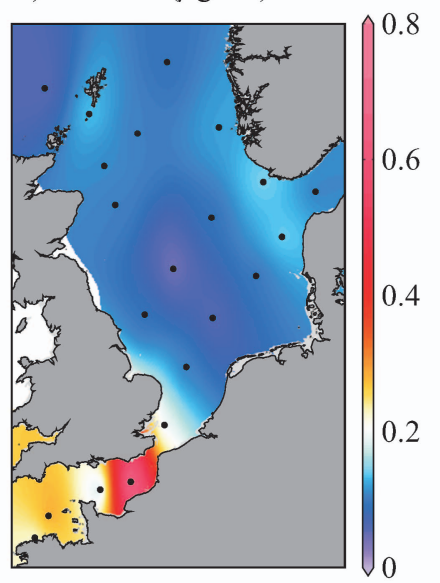

G) Total DGTS $\left(\mu \mathrm{g} \mathrm{L}^{-1}\right)$

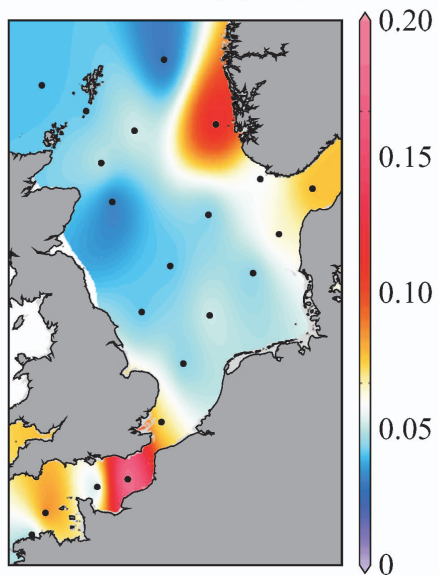

D) Total PE $\left(\mu \mathrm{g} \mathrm{L}^{-1}\right)$

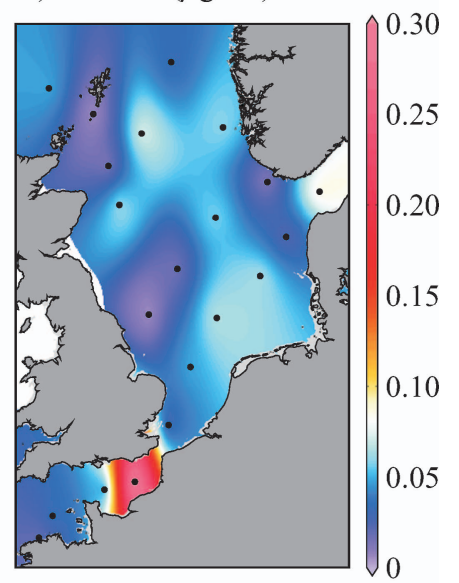

Fig. 6. Total concentrations of the predominant IPL classes (A) SQDG, (B) PC, (C) PG, (D) PE, (E) DGCC, (F) DGTA, and (G) DGTS in the surface waters of the North Sea and adjacent areas. The contour maps were obtained from concentration data at each station using the freeware package Ocean Data View 4 (Schlitzer 2010). Please note the differences in scale between each plot.

tal, and microbial data. Figure 7A shows the distribution of the stations based on the dissimilarity of their IPL composition, with stations that are similar clustering together and stations that are different lying further out. Similar plots were generated for the microbial and environmental data, and correlation of the three similarity matrices showed a weak but significant relationship between the IPL composition and the microbial community composition $(r=0.40, p=0.008)$, but not between the IPL composition and the environmental parameters $(r$ $=0.17, p=0.114$ ). Figure 7B shows how the distribution of the stations relates to the original data (IPL concentrations and microbial abundances), with the vectors showing the direction of the highest concentration or abundance. For example, the stations towards the lower right (MV01, MV03, MV06, and MV22) were characterized by high picoeukaryote and bacterial, but low cyanobacterial abundances. These same stations also had high concentrations of SQDG and PG species, as well as of several PC and DGTS species. Although the station distribution was skewed towards one particular station (MV05, where the diatom bloom produced very high IPL concentrations), analysis of the dataset while excluding MV05 resulted in comparable plots and identical clustering of the stations (data not shown).

The distance-based ordination shows that the stations in the English Channel, in the western North Sea, and off the Danish coast (cluster 1; open circles in Fig. 7A) were characterized by high concentrations of SQDG and PG species, whereas those in the central North Sea (cluster 2; closed circles in Fig. 7A) were characterized by high concentrations of PE, DGTA, and DGCC species. The PC and DGTS species occupied an intermediate position between these two groupings, and were high at stations in the eastern North Sea, the Skagerrak, and parts of the English Channel. Furthermore, the distributions of the PC and DGTS species were less uniform than those of the SQDG, PG, and PE species (as can be seen from their spread in vectors in Fig. 7B), and depended on their fatty acid composition. High concentrations of PC species with short-chain saturated or monounsaturated fatty acids coincided with high concentrations of SQDG and PG species, as well as high picoeukaryote abundances. In contrast, the PC species containing one or two long-chain 

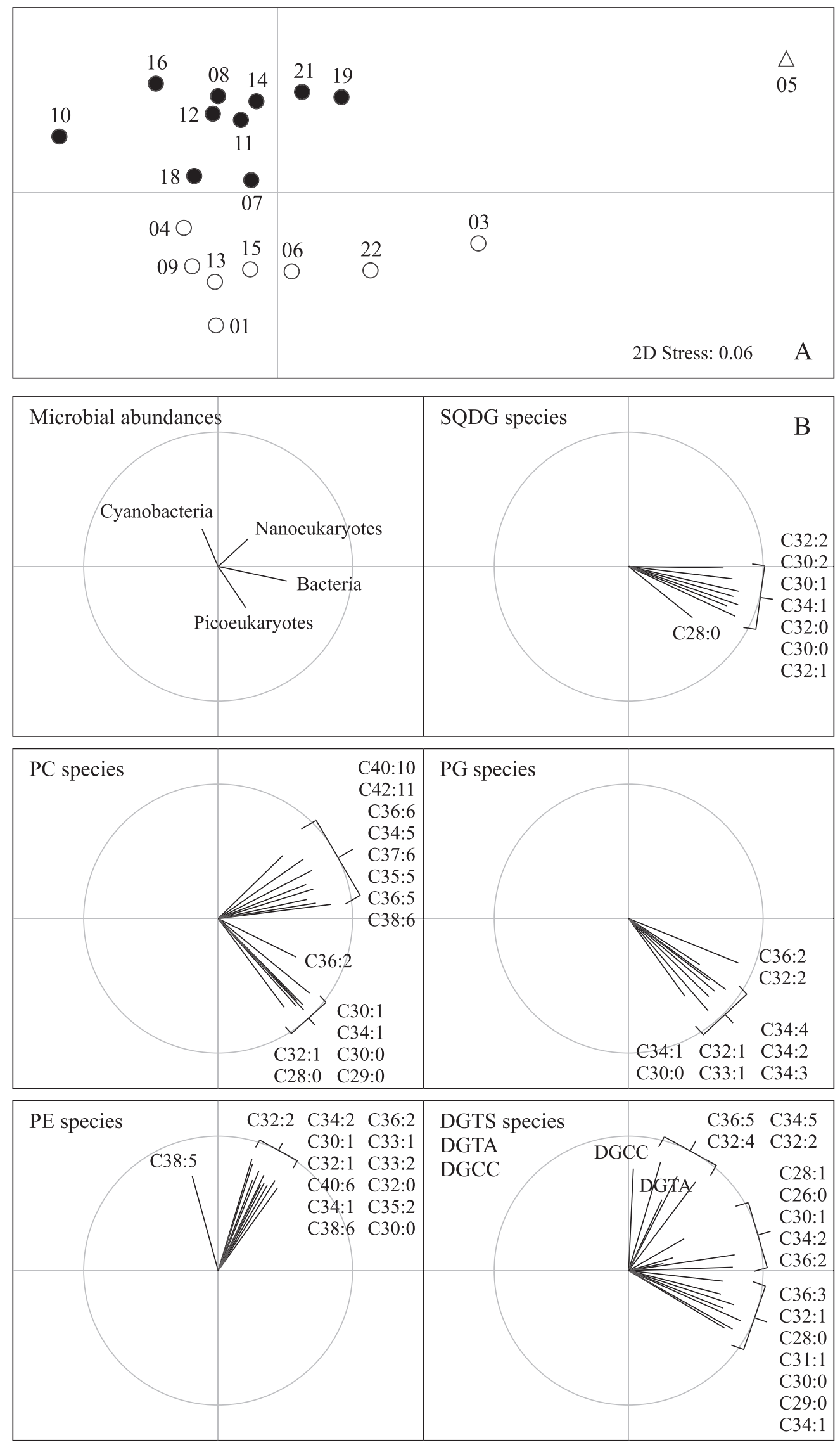
PUFAs coincided with high nanoeukaryote abundances. The division in the DGTS species was less clear-cut, and most of these had vectors intermediate between the other IPL species (Fig. 7B). However, all DGTS species containing PUFAs coincided with high concentrations of PUFAPC, PE, DGTA, or DGCC species, rather than with SQDG, PG, or non-PUFA PC species.

The trends observed in the initial comparison of the datasets were examined for their statistical significance by calculating the measure of association (Spearman's rank correlation coefficient: $r$ ) between each pair of parameters (see Web Appendix, Table A3). Almost no significant correlations were found between the environmental parameters (salinity, temperature, or nutrient concentrations) and IPL concentrations. However, the exception was the $\mathrm{N}: \mathrm{P}$ ratio, which was positively correlated with concentrations of total SQDG, PG, PC, and DGTS ( $r>0.54)$, as well as with most of their constituent IPL species. Positive correlations were also observed between concentrations of chlorophyll $a$ and total SQDG, PG, and PC $(r>0.69)$ and their species. Scatter plots revealed this last relationship to be linear for the log-transformed data, with $R^{2}$ values of 0.45 for total PG, 0.48 for total DGTS, 0.59 for total PC, and 0.61 for total SQDG $(n=14)$. To some extent chlorophyll $a$ concentrations also correlated with many of the DGTS species, but not with the PEs, DGTA, or DGCC.

Some significant correlations were found between microbial abundances and the total concentrations of the IPL classes. Total SQDG and PG $(r>0.62)$, and to some degree PC were positively correlated with picoeukaryotic abundances $(r>0.45)$, and all IPL classes were correlated with bacterial abundances $(r>0.40)$, except for total DGTA, which was the only class to correlate with cyanobacterial abundances $(r=0.65)$. The trends observed in the MDS ordination were mostly confirmed in the correlation pattern of the IPL species (Table A3). The SQDG and PG species, as well as the non-PUFA PCs and several DGTS species, correlated with picoeukaryote and bacterial abundances. In contrast, the PUFA-containing PC species correlated with nanoeukaryote rather than with picoeukaryote abundances. Most PE species correlated with bacterial abundances, but PE species containing either a $\mathrm{C}_{20: 5}$ or a $\mathrm{C}_{22: 6}$ fatty acid were possibly associated with nanoeukaryotes or cyanobacteria, as were a number of DGTS species. Thus, both MDS ordination and Spearman correlation identified three groups of IPL species that could be tentatively related to the major microbial groups, although the correlations were in most cases relatively weak.

\section{Discussion}

Influence of environmental parameters on IPL distributions - Statistical analyses revealed no significant correlations between IPL concentrations and sea surface temperature or salinity, which indicates that these parameters are unlikely to affect IPL distributions directly (Table A3). Similarly, no correlations were found with the concentrations of dissolved inorganic nutrients (i.e., phosphate, ammonium, $\mathrm{NO}_{\mathrm{x}}$, and silicate) in these waters. However, positive correlations were observed between concentrations of total SQDG, PG, PC, and DGTS and the N:P ratio. This ratio is generally seen as a measure for phosphate availability (Howarth 1988), although it should be applied with care, as it does not take into account the more rapid and complete turnover of phosphorus compared to nitrogen, meaning that phosphate is not necessarily the limiting nutrient during phytoplankton blooms (Dodds 2003). It has been shown that phytoplankton grown under phosphate limitation can rapidly substitute the glycerophospholipids PG and PC in their cellular membranes with non-phosphorous SQDG and betaine lipids (DGTS or DGCC), and it was proposed that elevated ratios of SQDG : PG and betaine lipids : PC in marine waters reflect reduced phosphate availability to the phytoplankton (Van Mooy et al. 2006, 2009; Martin et al. 2011). In our study area the $\mathrm{N}$ : $\mathrm{P}$ ratio ranged from less than 5 (potentially $\mathrm{N}$ limited) to 25 (potentially P limited), but despite this wide range of phosphate availability, no direct relationship of the $\mathrm{N}: \mathrm{P}$ ratio with the SQDG: $\mathrm{PG}$ ratio, the DGTS:PC ratio, or the DGCC: $\mathrm{PC}$ ratio was observed $\left(R^{2}<0.20, n=\right.$ $21)$. Instead, concentrations of these four IPLs generally covaried, with especially total SQDG and PGs, and PC and DGTS, positively correlated with each other (Table A3). This covariance thus appears to contradict the prediction that SQDG and DGTS should be found in elevated concentrations at stations with low phosphate availability, whereas PG and PC should be found in reduced concentrations (as per Van Mooy et al. 2009). However, it is important to note that this relationship between IPL ratios and phosphate limitation was originally observed for comparable microbial communities in oligotrophic open ocean settings, where dissolved $\mathrm{P}$ concentrations are low

Fig. 7. Distance-based ordination of the MICROVIR stations based on IPL species concentrations (MDS ordination of a BrayCurtis similarity matrix). The distance between stations in the upper panel (A) is a measure of their compositional dissimilarity, with most stations falling into two clusters (open or closed circles), except for the outlier Sta. MV05 (open triangle). The stations that fall within each cluster have $>80 \%$ similarity in their IPL composition, based on cluster analysis of the similarity matrix. The plots in the lower part of the figure (B) show how the IPL concentrations and the microbial abundances correspond with the spatial distribution of the stations. For example, the stations towards the lower right (MV01, MV03, MV06, and MV22) have high picoeukaryote and bacterial but low cyanobacterial abundances, as well as high concentrations of many SQDG, PG, PC, and DGTS species. 


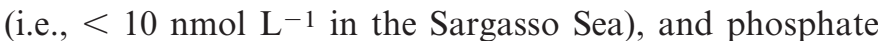
availability was not expected to influence IPL ratios above concentrations of $\sim 30 \mathrm{nmol} \mathrm{L}^{-1}$ (Van Mooy et al. 2009; Van Mooy and Fredricks 2010). As a shelf sea, the North Sea is more eutrophic than the open oceans, with dissolved $\mathrm{P}$ concentrations ranging from 10 to $300 \mathrm{nmol} \mathrm{L}^{-1}$ (Table 1). Combined with the more diverse microbial community composition (Brandsma 2011), this could explain why no relationship was found between IPL ratios and phosphate availability, and confirms that this relationship is probably limited to marine environments with low dissolved P concentrations. In conclusion, the general lack of correlation between the IPL concentrations and ratios and the environmental conditions thus implies that these were not a major controlling factor for the IPL diversity in the North Sea.

Potential sources of IPLs in the North Sea-Through statistical comparison of the IPL concentrations with the microbial abundances three distinct groups of IPLs were identified, which were significantly, albeit weakly, related to the main microbial groups (Fig. 7A; Table A3). The results were influenced to some degree by the comparatively high IPL concentrations at Sta. MV05, where the diatom bloom and associated heterotrophic bacteria produced concentrations of SQDG, PG, PC, PE, and DGTS that were on average 4-18 times higher than their concentrations over the rest of the North Sea (Fig. 6). Therefore, this site dominated the variability between the stations in the statistical analyses. Nonetheless, repeated analysis of the dataset showed that the results were comparable, whether Sta. MV05 was included or not.

The first group of IPLs identified through the statistical analyses comprised the SQDG and PG species, as well as PC species containing saturated fatty acid moieties and several DGTS species (Fig. 7B; Table A3). These IPLs had the highest concentrations at stations in the English Channel, in the southern and western North Sea, and off the Danish coast, and were related to the high picoeukaryote and bacterial abundances in these areas (Figs. 3, 7). The second group comprised the PUFA-PCs and several DGTS species, possibly including those with PUFAs, which were highest in the eastern North Sea, the Skagerrak, and parts of the English Channel. This group of IPLs correlated with the high nanoeukaryote abundances in these areas, although surprisingly the station with the highest nanoeukaryote cell count (Sta. MV16; Fig. 3C) did not show elevated concentrations of these IPLs at all (Fig. 6). The third group of IPLs comprised the PE, DGTA, and DGCC species, and possibly DGTS species containing PUFAs. This group of IPLs had the highest concentrations at stations in the central North Sea, which were characterized by high cyanobacterial and bacterial abundances (Figs. 3, 7). The statistical analyses thus implicate that discrete groups of IPLs are sourced by different microbial groups.

The observed relationships can be substantiated by comparing them with IPL compositions of cultivated microbes. SQDG is restricted to photosynthetic organisms, where it forms the main anionic IPL in thylakoid membranes (Benning 1988; Keusgen et al. 1997; Frentzen
2004). As SQDG has to date not been found in nonphotosynthetic heterotrophic bacteria, the correlations found with bacterial abundances are likely indirect, resulting from high numbers of heterotrophic bacteria occurring at sites of high photosynthetic phytoplankton biomass, in particular in the southern North Sea. Interestingly, total SQDG concentrations were correlated with picoeukaryote rather than nanoeukaryote abundances. Although this IPL probably occurs in both groups, it may be that the smaller picoeukaryotes contained comparatively more thylakoid membrane per cell, and thus contributed more to the total SQDG pool than the larger but four times less abundant nanoeukaryotes.

In contrast to SQDG, the glycerophospholipids PC, PG, and $\mathrm{PE}$ are common constituents of cellular membranes in most microorganisms, with PC mostly confined to eukaryotes and PE predominantly found in bacteria (Lechevalier and Lechevalier 1989; Sohlenkamp et al. 2003; Van Mooy and Fredricks 2010). PG is a more universal IPL class, as it is synthesized by both eukaryotes and prokaryotes, including cyanobacteria (Wood 1974; Lechevalier and Lechevalier 1989; Dowhan 1997), and is also found in small amounts in thylakoid membranes (Janero and Barrnett 1981; Frentzen 2004). Nonetheless, PG concentrations in the North Sea were mostly associated with picoeukaryote abundances, indicating that these were the predominant source of PG. A similar relationship was found between picoeukaryotes and non-PUFA PC species, whereas the PC species containing PUFAs were rather associated with nanoeukaryote abundances. Although long-chain PUFAs are commonly found in both algal groups (Shaw 1974; Volkman et al. 1998; Gushina and Harwood 2006), it thus appears that in the North Sea the larger nanoeukaryotes are the predominant source for PUFA-PCs. The relationships found for PE were more ambiguous than those found for the other glycerophospholipids. The Spearman test yielded significant correlations between total PE concentrations and bacterial abundances, which could in large part be explained by the elevated presence of both at Sta. MV05 (diatom bloom). On the other hand, the PE species containing PUFAs were not correlated with bacterial abundances, in line with the uncommon occurrence of such fatty acids in bacteria, and the distance-based ordination plots showed that overall the PE species were associated with stations with high cyanobacterial abundances (Fig. 7). However, PE has thus far not been found in cultivated cyanobacteria (Lechevalier and Lechevalier 1989; Van Mooy et al. 2006), and it is therefore likely that the PEs in the North Sea were mostly derived from heterotrophic bacteria.

The betaine lipids DGTS, DGTA, and DGCC are found in a wide range of eukaryotes (Sato 1992; Dembitsky 1996; Kato et al. 1996), as well as in cyanobacteria ( ̌ ezanka et al. 2003) and some photosynthetic bacteria (Klug and Benning 2001; Elshahed et al. 2007). Although betaine lipids are predominately found in cellular membranes, DGTS has also been found in minor amounts in thylakoid membranes (Janero and Barrnett 1982; Mendiola-Morgenthaler et al. 1985). In the North Sea, total DGTA and DGCC concentrations correlated with cyanobacterial abundances, 
Table 2. Average fatty acid chain lengths (number of carbon atoms) and degrees of unsaturation (double bond equivalents) of SQDG, PC, PG, PE, and DGTS in surface waters of the North Sea (this study) and the eastern South Pacific (approximate values obtained from figs. 8 and 9 in Van Mooy and Fredricks 2010). Note that the values refer to the combined fatty acid moieties and do not include the glycerol moiety.

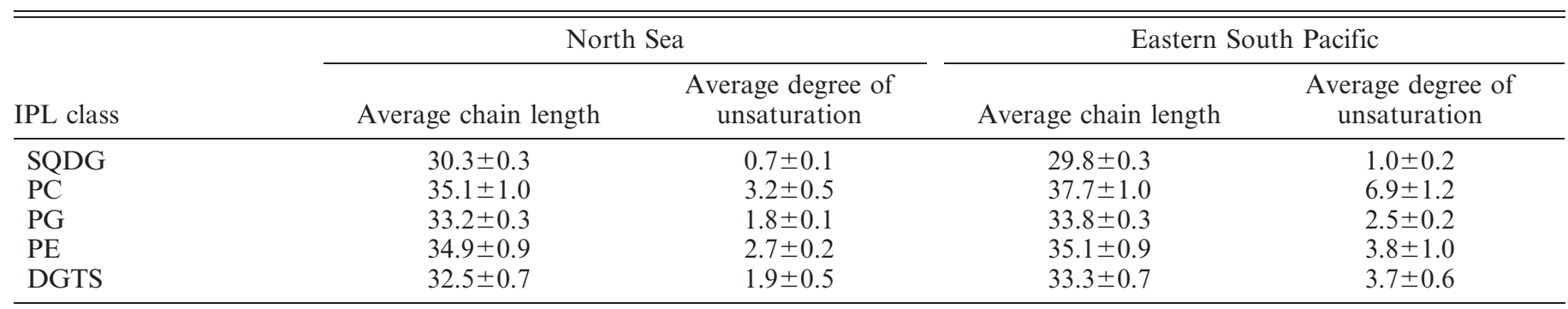

implying that this microbial group was the predominant source. Total DGTS concentrations were not related to any single microbial group, and in the distance-based ordination plots individual DGTS species occupied intermediate positions between the other IPL groupings (Fig. 7B), implying mixed sources for these IPLs. Most of the DGTS species appeared to be derived from either pico- or nanoeukaryotes, whereas some, including those containing PUFAs, were rather derived from either nanoeukaryotes or cyanobacteria (see also Van Mooy and Fredricks 2010).

IPL concentrations as a proxy for living biomass-Our statistical analysis shows that the IPL composition in the surface waters of the North Sea can be tentatively linked to the in situ microbial community composition. However, the overall measures of statistical dependence between the IPLs and microbial groups were relatively low, raising the question of how well they represent the in situ microbial biomass. Abundances of IPLs or IPL-derived fatty acids are widely used as a proxy for microbial biomass in environmental and biogeochemical studies (Petsch et al. 2001; Zink et al. 2003; Lipp et al. 2008), although the value of this proxy has recently been qualified to some extent for subsurface sediments (Schouten et al. 2010). Statistical comparison of the IPL concentrations in the North Sea surface waters with the chlorophyll a concentration, a measure for photosynthetic phytoplankton biomass (Huot et al. 2007), yielded good correlations for the eukaryotic IPL classes SQDG, PC, PG, and possibly DGTS, but not for the (cyano)bacterial classes PE, DGTA, and DGCC (Table A3). There thus appears to be a relationship between the amount of photosynthetic phytoplankton biomass and the concentrations of several IPL classes, which provides empirical evidence for the applicability of these compounds as a biomass proxy in marine waters. However, an exceptional situation was found at one of the stations (MV07), where chlorophyll $a$ concentrations were high, but IPL concentrations were comparable to those of other stations. It is possible that this site represents the situation where a phytoplankton bloom has recently crashed, with the chlorophyll $a$ molecules potentially having a longer residence time than the IPLs.

Comparison of the IPL composition of North Sea surface waters with other sites - Our study shows that there is a large diversity in IPLs in the surface waters of the North
Sea and adjacent areas. At least 600 different IPL species were recognized, and because each of these species may comprise multiple fatty acid compositions the total number of IPLs in a single surface water sample is likely to be much higher. Moreover, only the dominant IPLs in a mass window of 300-1000 Da were targeted here, and therefore the real structural diversity in IPLs could be even larger.

The IPL diversity within the current mass window was dominated by seven classes: SQDG, glycerophospholipids (PC, PG, and PE), and betaine lipids (DGCC, DGTA, and DGTS). Similar findings were made for the surface waters of the Black Sea (Schubotz et al. 2009), the Sargasso Sea and the Pacific Ocean (Van Mooy et al. 2006, 2009; Van Mooy and Fredricks 2010), and the western North Atlantic Ocean (Popendorf et al. 2011). However, mono- and digalactosyldiglycerides, which were abundant at these other sites, were only detected in minor amounts in the North Sea. The fatty acid compositions of the predominant IPL classes were generally comparable between the different locations. However, SQDG and PG species containing $\mathrm{C}_{18}$ PUFAs were detected in the Black Sea (Schubotz et al. 2009), but were rare (PG) or not detected (SQDG) in the North Sea and eastern South Pacific (Van Mooy and Fredricks 2010). Furthermore, a comparison of the fatty acid chain lengths and degrees of unsaturation of the predominant IPL classes in the North Sea and eastern South Pacific showed that the IPLs in the North Sea had either similar or lower (PC) average fatty acid chain lengths, and a lower average degree of unsaturation (Table 2). These differences were most pronounced in PC, which in the North Sea contained comparatively more short-chain saturated or mono-unsaturated fatty acids than long-chain PUFAs. Although no quantitative data are available from the Black Sea, at all three sites SQDG, PG, and DGTS had the shortest and most saturated fatty acid chains, whereas PC contained comparatively more longchain PUFAs. DGTA and DGCC contained the longest and most unsaturated fatty acids in the North Sea and eastern South Pacific, but unfortunately no distinction was made between the three types of betaine lipid in the Black Sea (Schubotz et al. 2009).

The general similarity between the IPL compositions observed in the North Sea and at other sites investigated to date suggests that the same suite of IPL classes, each with a broadly defined but distinct fatty acid profile, predominates in the surface waters of the world's oceans. The main 
difference between sites lies in the relative abundance of these IPL classes and to some degree their fatty acid compositions. This is quite striking and somewhat surprising as the investigated sites comprise rather different environments (e.g., eutrophic vs. oligotrophic, tropical vs. temperate) and therefore presumably contain different microbial communities. Although there is a relationship between the IPL composition in marine surface waters and the in situ microbial community composition, the overall comparatively low measures of statistical dependence, plus the fact that many of the IPLs do not appear to be specific for a single microbial group and predominate across a wide range of oceanographic settings, indicate that direct inferences of microbial community compositions from IPL compositions should be considered with care.

\section{Acknowledgments}

We thank Marianne Baas and the crew of R/V Pelagia for their help with sampling, Jan van Ooijen for the shipboard nutrient measurements, Joaquín Martínez Martínez for the microbiological analyses, Swier Oosterhuis for the chlorophyll $a$ measurements, Anna Noordeloos for providing the Isochrysis galbana culture, and Jan Geenevasen for the nuclear magnetic resonance spectroscopy analyses. We also thank B. A. S. Van Mooy and the anonymous reviewer for their valuable comments and suggestions to improve the manuscript. Financial support for this study was obtained from the Netherlands Organization for Scientific Research (NWO) Biogeosphere grant 853.00.012 and the Spinoza prize awarded to J.S.S.D.

\section{References}

BENNING, C. 1988. Biosynthesis and function of the sulfolipid sulfoquinovosyl diacylglycerol. Annu. Rev. Plant Physiol. Plant Mol. Biol. 49: 53-75, doi:10.1146/annurev.arplant.49.1.53

, Z.-H. Huang, AND D. A. Gage. 1995. Accumulation of a novel glycolipid and a betaine lipid in cells of Rhodobacter sphaeroides grown under phosphate limitation. Arch. Biochem. Biophys. 317: 103-111, doi:10.1006/abbi.1995.1141

Bligh, E. G., AND W. J. Dyer. 1959. A rapid method of total lipid extraction and purification. Can. J. Biochem. Physiol. 8: 911-917, doi:10.1139/059-099

BoumAnN, H. A., AND OTHERs. 2006. Ladderane phospholipids in anammox bacteria comprise phosphocholine and phosphoethanolamine headgroups. FEMS Microbiol. Lett. 258: 297-304.

BRANDSMA, J. 2011. The origin and fate of intact polar lipids in the marine environment. Ph.D. thesis. Univ. of Utrecht.

Brügger, B., G. Erben, R. Sandhoff, F. T. Wieland, and W. D. LEHMANN. 1997. Quantitative analysis of biological membrane lipids at the low picomole level by nano-electrospray ionization tandem mass spectrometry. Proc. Natl. Acad. Sci. USA 94: 2339-2344, doi:10.1073/pnas.94.6.2339

Dembitsky, V. M. 1996. Betain ether-linked glycerolipids: Chemistry and biology. Prog. Lipid Res. 35: 1-51, doi:10.1016/ 0163-7827(95)00009-7

DodDs, W. K. 2003. Misuse of inorganic $\mathrm{N}$ and soluble reactive $\mathrm{P}$ concentrations to indicate nutrient status of surface waters. J. North Am. Benthol. Soc. 22: 171-181, doi:10.2307/1467990

Dowhan, W. 1997. Molecular basis for membrane phospholipid diversity: Why are there so many lipids? Annu. Rev. Biochem. 66: 199-232, doi:10.1146/annurev.biochem.66.1.199

Ducrotoy, J.-P., M. Elliott, and V. N. De Jonges. 2000. The North Sea. Mar. Pollut. Bull. 41: 5-23, doi:10.1016/S0025-326X (00)00099-0
Elliott, A. J., And T. Clarke. 1991. Seasonal stratification in the northwest European shelf seas. Cont. Shelf Res. 11: 467-492, doi:10.1016/0278-4343(91)90054-A

Elshahed, M. S., AND Others. 2007. Phylogenetic and metabolic diversity of Planctomycetes from anaerobic, sulfide- and sulfur-rich Zodletone Spring, Oklahoma. Appl. Environ. Microbiol. 73: 4707-4716, doi:10.1128/AEM.00591-07

Evans, R. W., M. Kates, AND G. W. Wood. 1982. Identification of diacylglycerol- $O-(N, N, N$-trimethyl)-homoserine in the halotolerant alga, Dunaliella parva. Chem. Phys. Lipids 31: 331-338, doi:10.1016/0009-3084(82)90069-X

FAHY, E., AND OTHERS. 2005. A comprehensive classification system for lipids. J. Lipid Res. 46: 839-862, doi:10.1194/ jlr.E400004-JLR200

FAng, J., AND M. J. BARCelona. 1998. Structural determination and quantitative analysis of bacterial phospholipids using liquid chromatography/electrospray ionization/mass spectrometry. J. Microbiol. Methods 33: 23-35, doi:10.1016/S0167-7012(98)00037-2

Frentzen, M. 2004. Phosphatidylglycerol and sulfoquinovosyldiacylglycerol: anionic membrane lipids and phosphate regulation. Curr. Opin. Plant Biol. 7: 270-276, doi:10.1016/ j.pbi.2004.03.001

Gushina, I. A., And J. L. Harwood. 2006. Lipids and lipid metabolism in eukaryotic algae. Prog. Lipid Res. 45: 160-186, doi:10.1016/j.plipres.2006.01.001

Harvey, H. R., R. D. Fallon, and J. S. Patton. 1986. The effect of organic matter and oxygen on the degradation of bacterial membrane lipids in marine sediments. Geochim. Cosmochim. Acta 50: 795-804, doi:10.1016/0016-7037(86)90355-8

Howarth, R. W. 1988. Nutrient limitation of net primary production in marine ecosystems. Annu. Rev. Ecol. Syst. 19: 89-110, doi:10.1146/annurev.es.19.110188.000513

Huot, Y., M. Babin, F. Bruyant, C. Grob, M. S. Twardowski, AND H. Claustre. 2007. Does chlorophyll $a$ provide the best index of phytoplankton biomass for primary productivity studies? Biogeosciences 4: 853-868, doi:10.5194/bg-4-853-2007

Jaeschke, A., C. Rooks, M. Trimmer, J. C. Nicholls, E. C. Hopmans, S. Schouten, and J. S. Sinninghe Damsté. 2009. Comparison of ladderane phospholipids and core lipids as indicators for anaerobic ammonium oxidation (anammox) in marine sediments. Geochim. Cosmochim. Acta 73: 2077-2088, doi:10.1016/j.gca.2009.01.013

Janero, D. R., And R. Barrnett. 1981. Cellular and thylakoidmembrane phospholipids of Chlamydomonas reinhardtii $137+$. J. Lipid Res. 22: 1126-1130.

, AND - 1982. Isolation and characterization of an ether-linked homoserine lipid from the thylakoid membrane of Chlamydomonas reinhardtii 137+. J. Lipid Res. 23: 307-316.

Kato, M., M. SAKai, K. Adachi, H. Ikemoto, and H. SAno. 1996. Distribution of betaine lipids in marine algae. Phytochemistry 42: 1341-1345, doi:10.1016/0031-9422(96)00115-X

Keusgen, M., J. M. Curtis, P. Thibault, J. A. Walter, A. Windust, and S. W. Ayer. 1997. Sulfoquinovosyl diacylglycerols from the alga Heterosigma carterae. Lipids 32: 1101-1112, doi:10.1007/s11745-997-0142-9

Klug, R. M., And C. Benning. 2001. Two enzymes of diacylglyceryl-O-4' - $(N, N, N$,-trimethyl)homoserine biosynthesis are encoded by btaA and btaB in the purple bacterium Rhodobacter sphaeroides. Proc. Natl. Acad. Sci. USA 98: 5910-5915, doi:10.1073/pnas.101037998

Lechevalier, H., AND M. P. Lechevalier. 1989. Chemotaxonomic use of lipids - an overview, p. 869-902. In C. Ratledge and S. G. Wilkinson [eds.], Microbial lipids, v. 1. Academic.

LipP, J. S., AND K.-U. HinRichs. 2009. Structural diversity and fate of intact polar lipids in marine sediments. Geochim. Cosmochim. Acta 73: 6816-6833, doi:10.1016/j.gca.2009.08.003 
, Y. Morono, F. Inagaki, and K.-U. Hinrichs. 2008. Significant contribution of Archaea to extant biomass in marine subsurface sediments. Nature 454: 991-994, doi:10.1038/nature07174

Martin, P., B. A. S. Van Mooy, A. Heithoff, and S. T. DyHrman. 2011. Phosphorous supply drives rapid turnover of membrane phospholipids in the diatom Thalassiosira pseudonana. ISME J. 5: 1057-1060, doi:10.1038/ismej.2010.192

Mendiola-Morgenthaler, L., W. Eichenberger, and A. BoschetTi. 1985. Isolation of chloroplast envelopes from Chlamydomonas. Lipid and polypeptide composition. Plant Sci. 41: 97-104, doi:10.1016/0168-9452(85)90109-8

Minnikin, D. E., H. Abdolrahimzadeh, and J. Baddiley. 1974. Replacement of acidic phospholipids by acidic glycolipids in Pseudomonas diminuta. Nature 249: 268-269, doi:10.1038/249268a0

Otto, L., J. T. F. Zimmerman, G. K. Furnes, M. Mork, R. SAetre, AND G. Becker. 1990. Review of the physical oceanography of the North Sea. Neth. J. Sea Res. 26: 161-238, doi:10.1016/0077-7579(90)90091-T

Petsch, S. T., T. I. Eglinton, and K. J. Edwards. 2001. 14C-dead living biomass: evidence for microbial assimilation of ancient organic carbon during shale weathering. Science 292: 1127-1131, doi:10.1126/science. 1058332

Popendorf, K. J., M. W. Lomas, and B. A. S. Van Mooy. 2011. Microbial sources of intact polar diacylglycerolipids in the Western North Atlantic Ocean. Org. Geochem. 42: 803-811, doi:10.1016/j.orggeochem.2011.05.003

Řezanka, T., I. Víden, J. V. Go, I. Dor, and V. M. Dembitsky. 2003. Polar lipids and fatty acids of three wild cyanobacterial strains of the genus Chroococcidiopsis. Folia Microbiol. 48: 781-786, doi:10.1007/BF02931514

Rose, A. H. 1989. Influence of the environment on microbial lipid composition, p. 255-279. In C. Ratledge and S. G. Wilkinson [eds.], Microbial lipids, v. 2. Academic.

RÜtTers, H., H. SAss, H. CypionkA, ANd J. Rullkötter. $2002 a$. Phospholipid analysis as a tool to study complex microbial communities in marine sediments. J. Microbiol. Methods 48: 149-160, doi:10.1016/S0167-7012(01)00319-0

$\longrightarrow$, AND $\longrightarrow$ 2002b. Microbial communities in a Wadden Sea sediment core - clues from analyses of intact glyceride lipids, and released fatty acids. Org. Geochem. 33: 803-816, doi:10.1016/S0146-6380(02)00028-1

SAto, N. 1992. Betaine lipids. Bot. Mag. Tokyo 105: 185-197, doi:10.1007/BF02489414

SChlitzer, R. 2010. Ocean Data View 4. [Internet] http://odv.awi.de

Schouten, S., J. J. Middelburg, E. C. Hopmans, and J. S. SinNinghe Damsté. 2010. Fossilization and degradation of intact polar lipids in deep subsurface sediments: A theoretical approach. Geochim. Cosmochim. Acta 74: 3806-3814, doi:10.1016/j.gca.2010.03.029

Schubotz, F., S. G. Wakeham, J. S. Lipp, H. F. Fredricks, and K.-U. HinRichs. 2009. Detection of microbial biomass by intact polar membrane lipid analysis in the water column and surface sediments of the Black Sea. Environ. Microbiol. 11: 2720-2734, doi:10.1111/j.1462-2920.2009.01999.x

Shaw, N. 1974. Lipid composition as a guide to the classification of Bacteria. Adv. Appl. Microbiol. 17: 63-108, doi:10.1016/ S0065-2164(08)70555-0

Smittenberg, R. H., E. C. Hopmans, S. Schouten, and J. S. SinNinghe Damsté. 2002. Rapid isolation of biomarkers for compound specific radiocarbon dating using high-performance liquid chromatography and flow injection analysis-atmospheric pressure chemical ionization-mass spectrometry. J. Chromatogr. 978: 129-140, doi:10.1016/S0021-9673(02) 01427-9

Sohlenkamp, C., I. M. López-Lara, and O. Geiger. 2003. Biosynthesis of phosphatidylcholine in bacteria. Prog. Lipid Res. 42: 115-162, doi:10.1016/S0163-7827(02)00050-4

Sturt, H. F., R. E. Summons, K. Smith, M. Elvert, and K.-U. HINRICHS. 2004. Intact polar membrane lipids in prokaryotes and sediments deciphered by high-performance liquid chromatography/electrospray ionization multistage mass spectrometry-new biomarkers for biogeochemistry and microbial ecology. Rapid Commun. Mass Spectrom. 18: 617-628.

Vancanneyt, M., S. Witt, W.-R. Abraham, K. Kersters, and H. L. Fredrickson. 1996. Fatty acid content in whole-cell hydrolysates and phospholipid fractions of Pseudomonads: A taxonomic evaluation. Syst. Appl. Microbiol. 19: 528-540, doi:10.1016/S0723-2020(96)80025-7

Van Mooy, B. A. S., And H. F. Fredricks. 2010. Bacterial and eukaryotic intact polar lipids in the eastern subtropical South Pacific: Water-column distribution, planktonic sources, and fatty acid composition. Geochim. Cosmochim. Acta 74: 6499-6516, doi:10.1016/j.gca.2010.08.026

, G. Rocap, H. F. Fredricks, C. T. Evans, and A. H. Devol. 2006. Sulfolipids dramatically decrease phosphorous demand by picocyanobacteria in oligotrophic marine environments. Proc. Natl. Acad. Sci. USA 103: 8607-8612, doi:10.1073/pnas.0600540103

, AND OTHERs. 2009. Phytoplankton in the ocean use nonphosphorous lipids in response to phosphorous scarcity. Nature 458: 69-72, doi:10.1038/nature07659

Vogel, G., M. Woznica, H. Gfeller, C. Müller, A. A. Stämpfli, T. A. Jenny, ANd W. Eichenberger. 1990. 1(3),2Diacylglyceryl-3(1)-O-2' -(hydroxymethyl)( $N, N, N$-trimethyl)$\beta$-alanine (DGTA): A novel betaine lipid from Ochromonas danica (Chrysophyceae). Chem. Phys. Lipids 52: 99-109, doi:10.1016/0009-3084(90)90154-J

Volkman, J. K., S. M. Barrett, S. I. Blackburn, M. P. Mansour, E. L. Sikes, and F. Gelin. 1998. Microalgal biomarkers: A review of recent research developments. Org. Geochem. 29: 1163-1179, doi:10.1016/S0146-6380(98)00062-X

White, D. C., W. M. Davis, J. S. Nickels, J. D. King, and R. J. RoвbIE. 1979. Determination of the sedimentary microbial biomass by extractible lipid phosphate. Oecologia 40: 51-62, doi:10.1007/BF00388810

Wood, B. J. B. 1974. Fatty acids and saponifiable lipids, p. 236-265. In W. D. P. Stewart [ed.], Algal physiology and biogeochemistry. Univ. of California Press.

Zink, K.-G., H. Wilkes, U. Disko, M. Elvert, ANd B. Horsfield. 2003. Intact phospholipids - microbial "life markers" in marine deep subsurface sediments. Org. Geochem. 34: 755-769, doi:10.1016/S0146-6380(03)00041-X

Associate editor: Peter Hernes

Received: 03 June 2011

Accepted: 03 January 2012 Amended: 07 March 2012 